\title{
Mechanistic study of PFOS adsorption on kaolinite and montmorillonite
}

\author{
Ruiming Zhang, Wei Yan, Chuanyong Jing* \\ State Key Laboratory of Environmental Chemistry and Ecotoxicology, Research Center for Eco-Environmental Sciences, Chinese Academy of Sciences, \\ Beijing 100085, China
}

\section{H I G H L I G H T S}

- The mechanisms of PFOS adsorption on clay minerals are examined at molecular level.

- XANEFS analysis provides direct evidence for chemical adsorption.

- FTIR spectra in situ monitors the interaction process of PFOS with clay minerals.

- PFOS could insert into the interlayers of montmorillonite.

- The HA coating decreased PFOS adsorption on kaolinite and montmorillonite.

\section{A R T I C L E I N F O}

\section{Article history:}

Received 9 June 2014

Received in revised form 1 August 2014

Accepted 11 September 2014

Available online 23 September 2014

\section{Keywords:}

Adsorption

Perfluorooctane sulfonate (PFOS)

Kaolinite

Montmorillonite

Chemisorption

Outer-sphere complexes

\section{G R A P H I C A L A B S T R A C T}

\begin{abstract}
A B S T R A C T
Adsorption of perfluorooctane sulfonate (PFOS) on clay minerals is pivotal in the fate and transport of PFOS in the environment. Understanding the PFOS adsorption mechanisms, however, presents challenges, especially in the presence of natural organic substances. In this study, the adsorption mechanism of PFOS on kaolinite and montmorillonite, with and without humic acids (HA), were investigated using batch experiments, ATR-FTIR spectroscopy, zeta potential, NEXAFS, and XRD. The results showed that PFOS had a higher adsorption capacity on kaolinite than on montmorillonite, both with a rapid formation of an outer-sphere complex followed by a slow ligand exchange reaction with the elimination of adsorbed $\mathrm{H}_{2} \mathrm{O}$ molecules. In addition to nonspecific hydrophobic and electrostatic interactions, specific chemisorption also exists between sulfonate group of PFOS and hydroxyl group on surfaces of clay minerals. The HA coating on clay materials inhibited PFOS adsorption due to its occupation of adsorption sites and increased electrostatic repulsion. The insights gained from this study improve our understanding on the mechanism of multilateral forces on PFOS adsorption at the molecular level.
\end{abstract}

(c) 2014 Elsevier B.V. All rights reserved.

\section{Introduction}

Perfluorooctane sulfonate (PFOS), widely used as surfactant, fire retardant, and paint $[1,2]$, has been categorized as a persistence organic pollutant since 2009 Stockholm convention [3]. PFOS is

\footnotetext{
* Corresponding author. Tel.: +86 106284 9523; fax: +861062849523.

E-mail address: cyjing@rcees.ac.cn (C. Jing).
}

detected in air, water, sediment, soil, human blood, and wildlife tissues around the world [4-6]. The ubiquitous occurrence of PFOS has motivated extensive studies on its mineral-water interfacial behavior [4-6], which is crucial in the fate and transport of PFOS in the environment [7].

Clay minerals participate in many important environmental processes [8,9]. Kaolinite and montmorillonite are widely used model clay minerals in mechanistic adsorption studies [10,11]. The two clay minerals have similar components but with stark 
structural difference. Specifically, kaolinite consists of one tetrahedral silica sheet fused to one octahedral alumina sheet, whereas montmorillonite contains one octahedral and two tetrahedral layers $[12,13]$. We speculate that the structural difference of kaolinite and montomorillonite may result in the different PFOS adsorption behaviors and mechanisms.

PFOS adsorption on clay minerals is mainly ascribed to electrostatic interactions and hydrophobic effect [9,14-16]. For example, electrostatic interactions as well as hydrophobic effect contribute PFOS adsorption on Ottawa sand, iron-coated sand, kaolinite, and goethite [14]. As a further evidence of electrostatic interactions, the increase in $\mathrm{pH}$ which consequently enhanced the electrostatic repulsion, decreased the PFOS adsorption on silica [15] and kaolinite [9]. In addition, PFOS adsorption would rise as the enhancement of the hydrophobic interaction by increasing the organic carbon content of adsorbents and perfluorocarbon chains [16]. Previous studies, however, intensively rely on macroscopic experimental results such as kinetics, isotherms, and $\mathrm{pH}$ adsorption envelops to propose adsorption mechanisms. The motivation of our study is, therefore, to investigate the mechanisms of PFOS adsorption on clay minerals at the molecular level to understand its fate and transport in the environment.

Humic acid (HA) is a major component of organic matter and plays a predominant role in many physical, chemical and geochemical processes in the environment $[17,18]$. HA is generally attached with clay minerals, and thus significantly affects their surface electrostatic properties. HA can also compete with pollutant molecules for available surface adsorption sites and subsequently impact the pollutant's interaction with clay minerals $[19,20]$. Thus, in this study, HA was coated on clay minerals to simulate the real environment in exploring the HA effect on PFOS adsorption.

The objective of this work was to explore the adsorption mechanism of PFOS on kaolinite and montmorillonite at the molecular level. Multiple complementary techniques were used including adsorption experiments, zeta potential, in situ attenuated total reflectance Fourier transform infrared (ATR-FTIR) spectroscopy, Xray diffraction (XRD), and near-edge X-ray absorption fine structure (NEXAFS) spectroscopy. The insights gained from this study would improve our understanding of the fate and transport of PFOS in the environment.

\section{Materials and methods}

\subsection{Materials}

Perfluorooctane sulfonate (PFOS, potassium salt; purity $\geq 98 \%$ ) was obtained from AccuStandard, Inc. (New Haven, CT, USA). Humic acid (HA) was purchased from Fluka (Chemie AG, Chemika/Biochemika, Buchs, Switzerland). Ammonium acetate, sodium hydroxide, and sodium chloride in analytical reagent grade were obtained from Sinopharm chemical reagent Co., Ltd. (Shanghai, China). Acetonitrile (HPLC grade) was from Fisher Scientific (Fair lawn, NJ, USA). The reagents were used without further purification. Milli-Q water (18.2 $\mathrm{M} \Omega$, Millipore, USA) was used in all experiments.

Kaolinite (KGa-1b) and montmorillonite (STx-1b) were from the Clay Minerals Society (The Source Clays Repository, Purdue University, USA). The particle size of montmorillonite and kaolinite are $842.9 \pm 125.9 \mathrm{~nm}$ for KGa-1b, and $1187.0 \pm 380.8 \mathrm{~nm}$ for STx$1 \mathrm{~b}$ [21]. The BET surface areas of kaolinite and montmorillonite are $11.9 \mathrm{~m}^{2} \mathrm{~g}^{-1}$ and $82.9 \mathrm{~m}^{2} \mathrm{~g}^{-1}$, respectively. Kaolinite and montmorillonite were purified with $\mathrm{NaCl}$ solution according to our previous report [22]. Briefly, Na-clays were prepared by adding $10 \mathrm{~g}$ clay minerals in $200 \mathrm{~mL} 0.1 \mathrm{M} \mathrm{NaCl}$ solution, then the samples were stirred for $8 \mathrm{~h}$ and washed till chloride free. The extractions of minerals at a solid/water ratio of 1:10 showed no existence of PFOS in KGa-1b and STx-1b.

\subsection{Preparation of HA coated clay minerals}

The coating of HA on clay minerals was modified from a previous report [19]. Briefly, the HA solution was prepared by dissolving $100 \mathrm{mg} \mathrm{HA}$ in $1.0 \mathrm{~L}$ water, and the $\mathrm{pH}$ was adjusted to 10.0 with $\mathrm{NaOH}$. The solution was sonicated for $10 \mathrm{~min}$ before passing through a $0.45-\mu \mathrm{m}$ filter. After filtration, the solution $\mathrm{pH}$ was adjusted to 7.0. Then, $100 \mathrm{~mL}$ above HA solution was mixed with $10 \mathrm{~g}$ minerals for two weeks at room temperature $\left(22 \pm 1^{\circ} \mathrm{C}\right)$. The suspension was centrifuged at $8000 \mathrm{rpm}$ for $30 \mathrm{~min}$ and the solid was dried at $60^{\circ} \mathrm{C}$. The TOC contents before and after the HA coating process were determined using a Phoenix 8000 Total Organic Carbon (TOC) Analyzer (Tekmar-Dohrmann, USA).

\subsection{Batch adsorption experiments}

Adsorption experiments were performed in the $50 \mathrm{~mL}$ polypropylene centrifuge tubes containing $40 \mathrm{~mL}$ of $1.9 \mu \mathrm{mol} \mathrm{L}^{-1}$

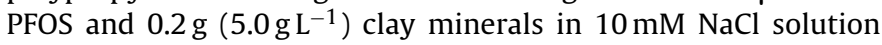
at $\mathrm{pH} 7.0 \pm 0.1$. Triplicate suspension samples were mixed on a rotator at $40 \mathrm{rpm}$ for $48 \mathrm{~h}$ before centrifugation at $8000 \mathrm{rpm}$ for $30 \mathrm{~min}$. The dissolved PFOS concentration was then analyzed using a high performance liquid chromatography-mass spectrometer (HPLC-MS, Waters ZQ4000, Waters, USA) with a detection limit of $1.5 \mu \mathrm{g} \mathrm{L}{ }^{-1}$ according to a previous report [23]. Triplicate control tests in the absence of clay minerals verified that the loss of PFOS is negligible. The solid samples for the following NEXAFS and XRD analysis were prepared in the same way with an initial PFOS concentration of $370 \mu \mathrm{mol} \mathrm{L}^{-1}$, which is lower than the reported Critical Micelle Concentration (CMC) of PFOS in water $\left(1 \mathrm{mmol} \mathrm{L}^{-1}\right.$ [24]).

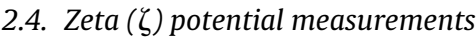

Zeta $(\zeta)$ potential measurements were carried out on a Malvern Zetasizer Nano ZS (Malvern Instruments, U.K.). The $\mathrm{pH}$ of the suspensions containing $0.2 \mathrm{~g} \mathrm{~L}^{-1}$ clay minerals and $18.5 \mu \mathrm{mol} \mathrm{L}^{-1}$ PFOS in $10 \mathrm{mM} \mathrm{NaCl}$ solution was adjusted in a range of 3.0-11.0 using $\mathrm{NaOH}$ and $\mathrm{HCl}$. Suspension samples were placed on a rotator at $40 \mathrm{rpm}$ for $48 \mathrm{~h}$ and the final $\mathrm{pH}$ was measured. The reported $\zeta$ potential value was the average of three measurements.

\subsection{In situ ATR-FTIR spectroscopy}

The in situ FTIR experiments were carried out on a Nicolet 6700 Fourier transform infrared spectrometer equipped with a mercury-cadmium-telluride (MCT) detector. A multibounce $\mathrm{ZnSe}$ ATR crystal with $45^{\circ}$ beveled faces (infrared angle of incidence, $\theta$ ) was used and the infrared spectra were collected using 256 scans per spectrum at a resolution of $4 \mathrm{~cm}^{-1}$. A $10 \mathrm{mM} \mathrm{NaCl}$ solution at pH 5.0 was used for electrolyte solution and PFOS solution. The FTIR measurements were described in our previous publication [25]. Briefly, each $0.5 \mathrm{~mL}$ of $1.0 \mathrm{~g} \mathrm{~L}^{-1}$ clay materials suspension was added to ZnSe crystal, and evaporated the water at $60^{\circ} \mathrm{C}$ to form a thin film. The flow cell with the coated film was washed with $10 \mathrm{mM}$ $\mathrm{NaCl}$ solution using a LC pump (LC 10A, Shimadzu Corp.) at a flow rate of $0.3 \mathrm{~mL} \mathrm{~min}^{-1}$ to flush out the uncoated particles and to reach equilibrium at the experimental $\mathrm{pH}$ values. The background IR spectrum was collected and saved. The electrolyte solution was then changed to $0.7 \mathrm{mmol} \mathrm{L}^{-1}$ PFOS at the same $\mathrm{pH}$ value as that of electrolyte solution. When PFOS adsorption reached equilibrium, the 
solution was then changed back to the electrolyte for the desorption cycle. All of the samples were purged with $\mathrm{N}_{2}$ in dark during the spectra collection. All data collection and spectral calculations were performed using OMNIC software (version 8.0, Nicolet Instrument Corp.).

\subsection{NEXAFS study}

The solid residues were freeze-dried, finely grounded, and dusted on a sulfur-free Mylar tape. The sulfur K-edge NEXAFS spectra were collected on the beamline 4B7A at Beijing Synchrotron Radiation Facility (BSRF), China. The spectra for adsorption samples were collected in fluorescence mode using a silicon drift detector positioned $45^{\circ}$ to the incident beam. The total electron yield mode was used to collect spectra for the standards including PFOS, SOS, SDS, $\mathrm{Na}_{2} \mathrm{~S}, \mathrm{KSCN}, \mathrm{H}_{2} \mathrm{HCSNH}_{2}, \mathrm{NaHSO}_{3}, \mathrm{Na}_{2} \mathrm{SO}_{3}, \mathrm{FeSO}_{4}$, and $\mathrm{K}_{2} \mathrm{SO}_{4}$. The spectra were energy calibrated by setting the K-edge of $\mathrm{K}_{2} \mathrm{SO}_{4}$ to $2482.6 \mathrm{eV}$ [26], and background corrected, and normalized using Athena [27].

\subsection{XRD analysis}

The basal spacing of kaolinite and montmorillonite with adsorbed PFOS were investigated using XRD analysis. The wet solid residues from the batch adsorption experiments were evenly coated on the platinum platform to obtain thin clay films. The XRD patterns were recorded from $4^{\circ}$ to $25^{\circ}$ using an X'Pert PRO instrument (PANalytical, The Netherlands) with $\mathrm{Cu} \mathrm{K \alpha}$ radiation $\left(n=1.5418 \AA\right.$ ) at $25^{\circ} \mathrm{C}$.

\section{Results and discussion}

\subsection{Batch adsorption experiment}

The PFOS adsorption on kaolinite and montmorillonite at $\mathrm{pH} 7.0$ reached $77.6 \pm 3.3$ and $54.5 \pm 7.2 \mu \mathrm{gg}^{-1}$, respectively, with an initial concentration of $1.9 \mu \mathrm{mol} \mathrm{L}^{-1}$ PFOS and $5.0 \mathrm{~g} \mathrm{~L}^{-1}$ clay minerals (Fig. 1). The surface area normalized adsorption were $7.4 \times 10^{-3}$ molecules per $\mathrm{nm}^{2}$ for kaolinite and $0.7 \times 10^{-3}$ molecules per $\mathrm{nm}^{2}$ for montmorillonite (Table S1). The results show that more than 10

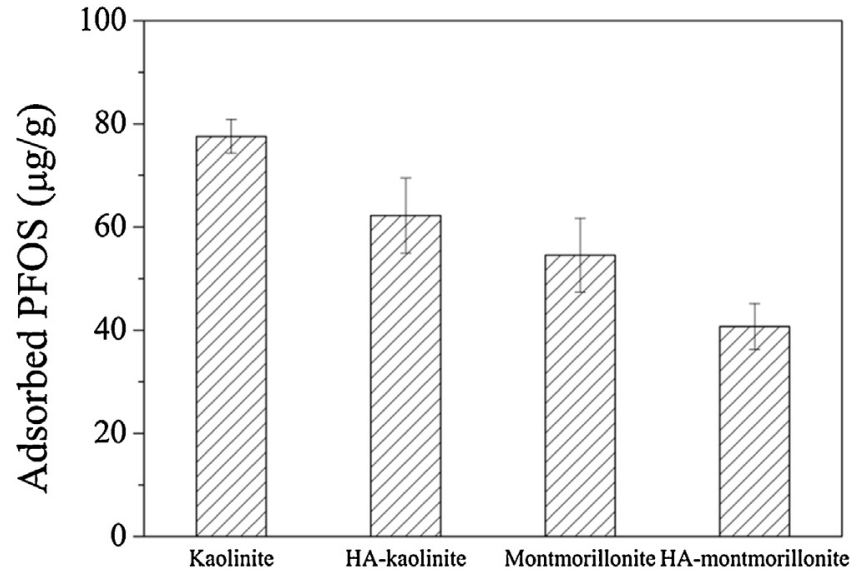

Fig. 1. Adsorption capability of $1.0 \mathrm{mg} \mathrm{L}^{-1}$ PFOS on $5.0 \mathrm{~g} \mathrm{~L}^{-1}$ adsorbents at $\mathrm{pH} 7.0$ in $10 \mathrm{mM} \mathrm{NaCl}$ solution.

times of PFOS molecules were adsorbed on kaolinite rather than on montmorillonite, suggesting kaolinite could provide more active sites for PFOS adsorption than montmorillonite.

Fig. 2 shows the zeta potentials of kaolinite and montmorillonite in the presence and absence of PFOS. The point of zero charge (PZC) of kaolinite was 3.2, whereas that of montmorillonite was less than 2.0. The results indicate that in the $\mathrm{pH}$ range 5.0-7.0, the clay minerals were negatively charged and kaolinite resulted in an even less negative charge than montmorillonite at the same $\mathrm{pH}$ values. Because PFOS was negatively charged in a wide $\mathrm{pH}$ range $\left(\mathrm{p} K_{\mathrm{a}}=-3.27[3]\right)$, the electrostatic repulsion between PFOS and clay minerals should inhibit the uptake of PFOS (Fig. 2), and such repulsion is greater on montmorillonite than on kaolinite. If only electrostatic interactions presented between PFOS and clay minerals, no PFOS adsorption would occur. Conversely, the PFOS adsorption on these two clay minerals was observed in our experiments, suggesting that adsorption mechanisms other than electrostatic interactions should exist.

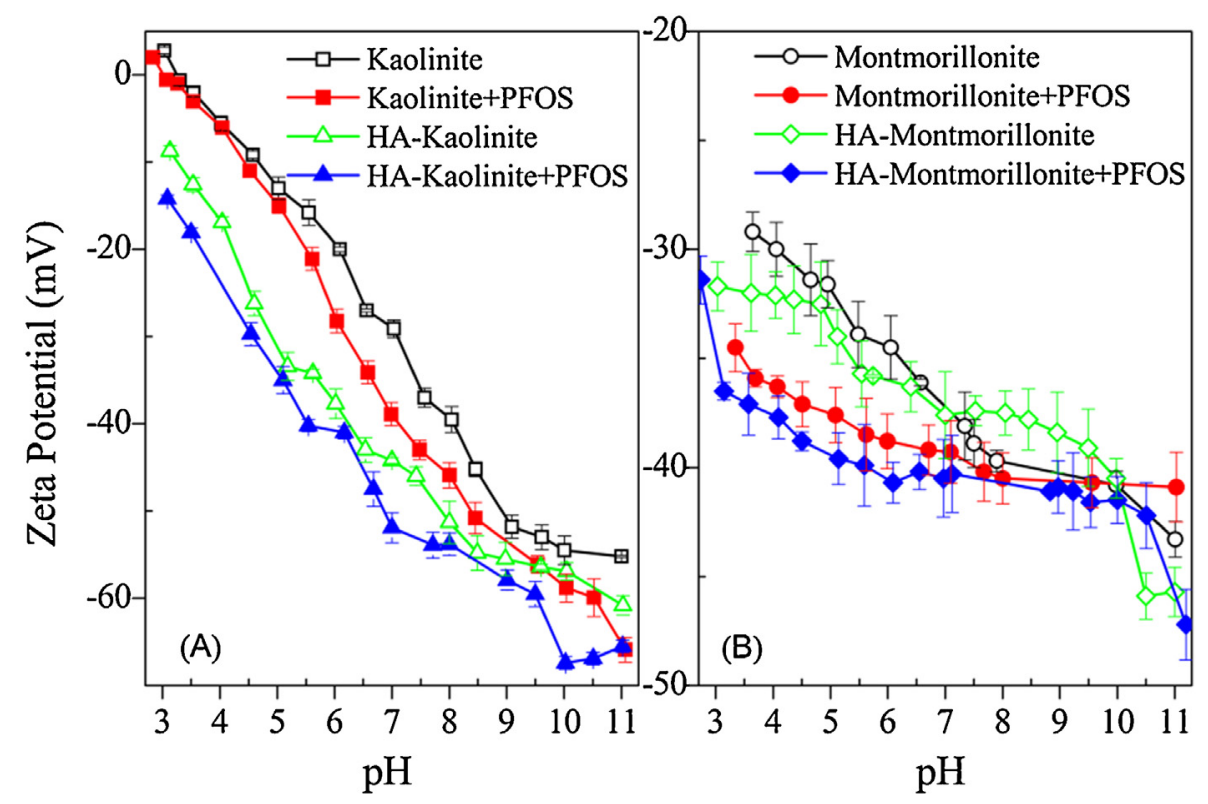

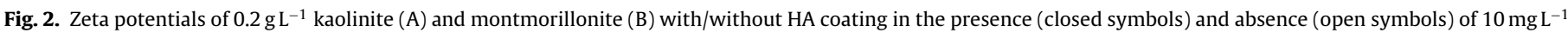

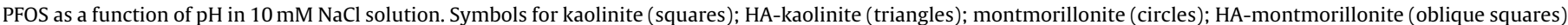




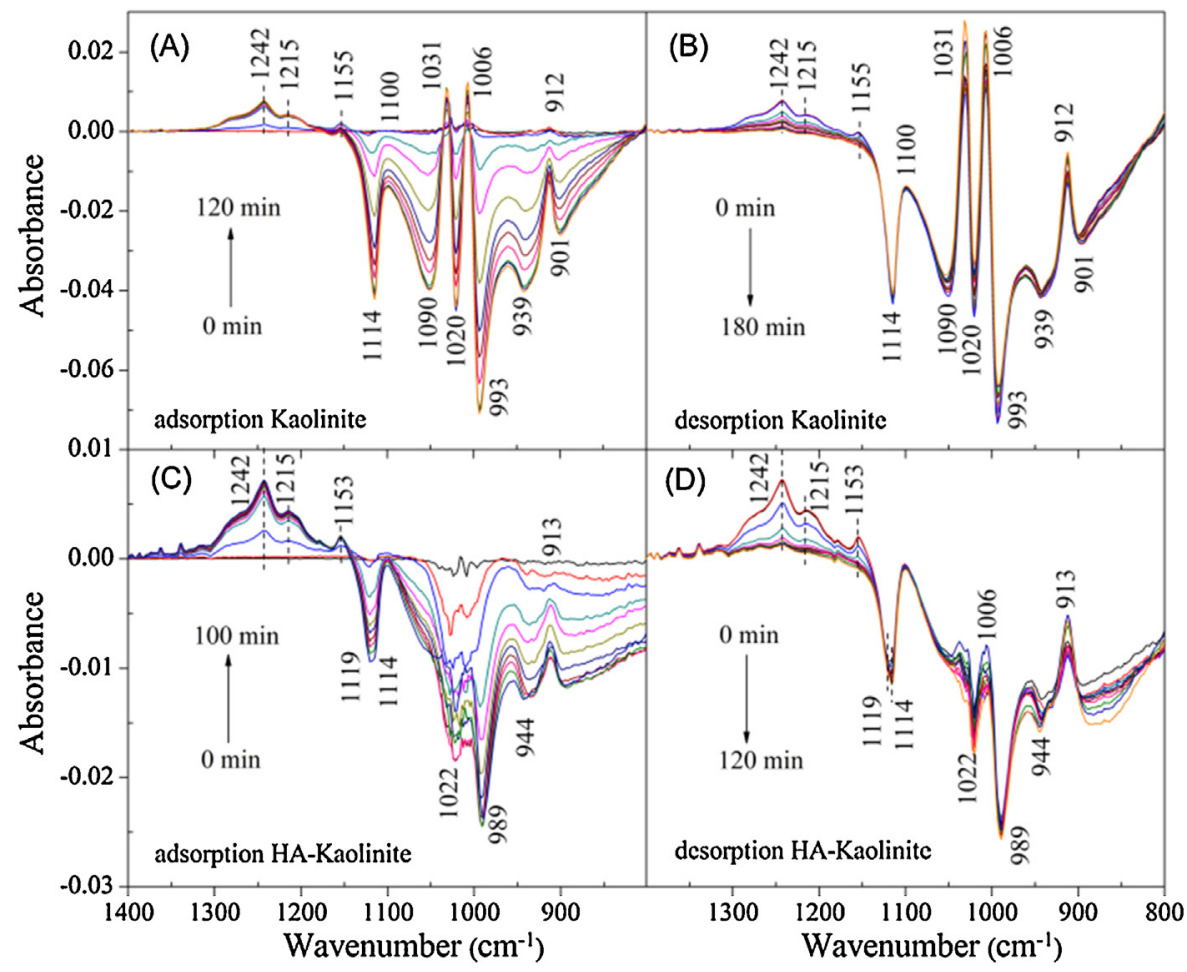

Fig. 3. ATR-FTIR spectra of PFOS adsorption and desorption onto kaolinite and HA-kaolinite at pH 5.0 in $10 \mathrm{mM} \mathrm{NaCl}$ as a function of time with a rate of $0.3 \mathrm{~mL}$ min ${ }^{-1}$.

\subsection{FTIR analysis}

To monitor the real-time interactions between PFOS and clay minerals, in situ ATR-FTIR spectroscopy was employed. The dissolved PFOS was used as a reference, and its spectrum and peak assignments are shown in Fig. S1 and Table S2, respectively. The characteristic peaks of PFOS were resolved at 1244 and $1152 \mathrm{~cm}^{-1}$, corresponding to asymmetric and symmetric stretching bands of $\mathrm{CF}_{2}$ [28], respectively.

The spectra of adsorbed PFOS on the two clay minerals were similar to that of the aqueous PFOS (Figs. 3 and 4 and Fig. S2). This high similarity in FTIR spectra suggested that the adsorption of PFOS as an outer-sphere complex should play a dominant role, in line with a previous report [28]. Here, the driving force for the outer-sphere adsorption of PFOS might be hydrophobic interaction $[9,13,15]$.

Notably, the negative peaks in the range $800-1200 \mathrm{~cm}^{-1}$ were resolved which were ascribed to the dissolution of silicic group (e.g. 1006, 1031, 1090, $1114 \mathrm{~cm}^{-1}$ for $\mathrm{Si}-\mathrm{O}$ stretching vibration) and aluminous group (e.g. $912 \mathrm{~cm}^{-1}$ for $\mathrm{Al}-\mathrm{OH}$ deformation) on the clay minerals (Figs. 3 and 4, Table S3). Before FTIR signals were collected, the clay minerals films had been equilibrated with the electrolyte solution, and therefore, the dissolution should be facilitated by the surface reactions between PFOS and clay minerals. These interactions may be ligand exchange [29], and acid-base reaction $[21,30]$. Because the sulfonate group is a hard base and clay minerals are hard acids [9,21], the hard base is readily adsorbed on clay surfaces based on the hard-soft-acid-base (HSAB) reaction theory. The results indicate that both the hydrophobic $\mathrm{C}-\mathrm{F}$ chain and the functional sulfonate group could affect PFOS adsorption on clay minerals. This conclusion was further justified by the following kinetic study using the parabolic diffusion model.

\subsection{Adsorption-desorption kinetics of PFOS}

To understand the adsorption dynamics, the kinetics of adsorption and desorption were characterized by the change in FTIR peak intensity of $v_{\text {as }}\left(\mathrm{CF}_{2}\right)$ band centered at $1244 \mathrm{~cm}^{-1}$ (Fig. 5). The kinetics of PFOS adsorption and desorption followed the parabolic diffusion model well $\left(R^{2}>0.842\right.$, Fig. 5, Table S4). Generally, the parabolic diffusion indicates that the diffusion-controlled phenomena are rate-limiting. In our study, PFOS adsorption process was similar to those of anionic surfactants and can be divided into two processes including a rapid formation of an outer-sphere complex followed by a slow ligand exchange reaction with the elimination of adsorbed $\mathrm{H}_{2} \mathrm{O}$ molecules [31,32]. The second slow process lasted about 80 min which was the rate controlling step in PFOS adsorption. In addition, the PFOS desorption process also showed a two-step process (Fig. 5). The initial rapid decrease was mainly due to the removal of weakly adsorbed PFOS [33]. Our FTIR kinetics results indicated that physical and chemical interactions occurred for PFOS adsorption on clay minerals. To testify the chemical nature in PFOS adsorption, we employed the following NEXAFS study.

\subsection{NEXAFS analysis}

NEXAFS is sensitive to the structure change near the target atom, and is used as a probe for the chemical state of sulfur in minerals and chemical compounds [34]. Because sulfonate group serves as the functional and active moiety in PFOS molecules, S K-edge NEXAFS can be applied to the structural analysis for PFOS surface complex. The PFOS spectrum exhibited a strong white line peak at $2481.2 \mathrm{eV}$ (Fig. 6), which originates from the excitation of S $1 \mathrm{~s}$ core electrons into unoccupied S $3 p$ orbitals [35]. The broad peak in the range $2479.0-2484.0 \mathrm{eV}$ was primarily attributed to the number and nature of first coordination shell around the scattering $S$ atom $(\mathrm{S}-\mathrm{O}, \mathrm{S}=\mathrm{O}, \mathrm{S}-\mathrm{C})$, and also to the next nearest-neighbor atoms including $\mathrm{K}, \mathrm{C}$, and $\mathrm{F}$, as well as metal atoms on surfaces [26].

Upon PFOS adsorption, three pre-edge peaks were observed at 2467.8, 2473.8, and $2476.4 \mathrm{eV}$ for kaolinite, and 2473.8, 2476.4 and $2478.4 \mathrm{eV}$ for montmorillonite (Fig. 6B). The pre-edge peaks are usually ascribed to the presence of low oxidation state of $S$ 


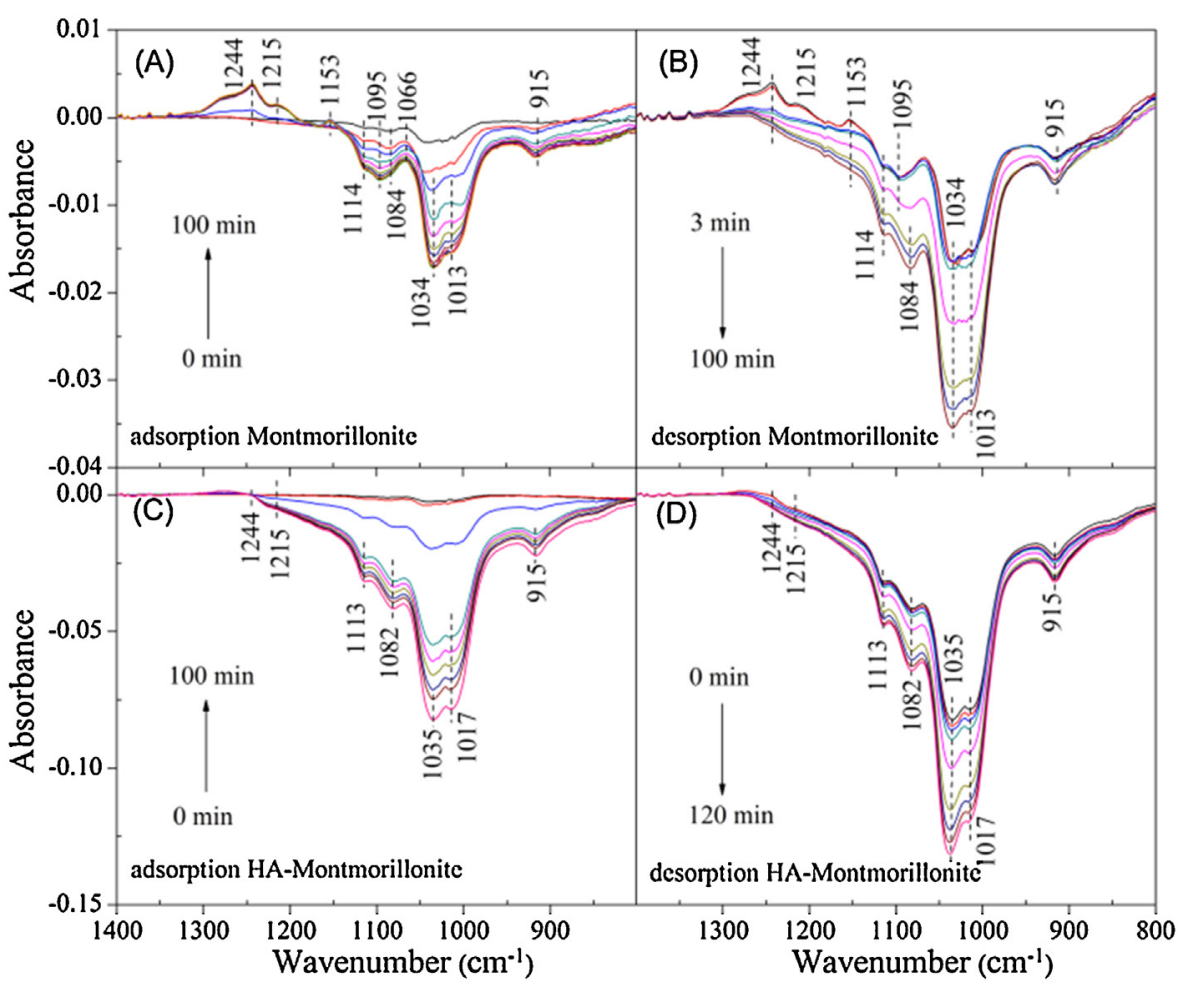

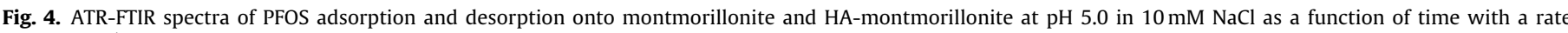
$0.3 \mathrm{~mL} \mathrm{~min}^{-1}$.

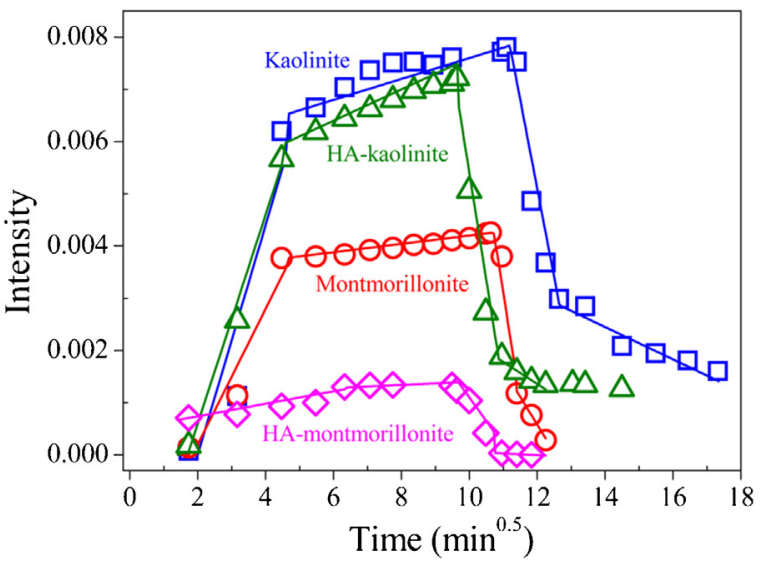

Fig. 5. FTIR peak intensity of PFOS at $1244 \mathrm{~cm}^{-1}$ on different adsorbents at pH 5.0 as a function of time. Symbols for kaolinite $(\square)$; montmorillonite $(\bigcirc)$; HA-kaolinite $(\Delta)$; HA-montmorillonite $(\diamond)$. Solid line stands for the parabolic diffusion model fitting.

[36-38]. However, the observed pre-edge peaks in this study were not induced by other lower valence $S$-compounds, as evidenced by the failure in matching their peak positions with reference compounds (Fig. 6A) [37]. Not surprisingly, PFOS would not transform to other S-containing compounds upon adsorption because of its high chemical stability. Thus, such pre-edge peaks indicated that the symmetry or local coordinates of S atom was changed after PFOS adsorption on kaolinite and montmorillonite.

The hybridization between $S 3 p$ and unoccupied transition metal $d$ orbitals has been reported to induce $S$ pre-edge peaks $[39,40]$. Interestingly, such hybridization occurred in spite of the presence of oxygen atom that separate sulfur from transition metal ions [41]. In agreement with our observations, the $S$ and $P$ pre-edge peaks were reported in transition-metal sulphate and phosphate
$[41,42]$. These pre-edge peaks can arise only if transition metal ion is bounded to $\mathrm{S}$ via a bridging $\mathrm{O}$ [43], corresponding to an inner-sphere complex at the solid/aqueous interface. Our NEXAFS analysis demonstrated the chemisorption nature of PFOS on clay minerals.

\subsection{XRD analysis}

To test whether the interlayer intercalation could be an important contributor to PFOS adsorption, the XRD patterns for PFOS-free and PFOS-adsorbed clay minerals were investigated. The XRD patterns of kaolinite with and without PFOS adsorption showed no significant change (Fig. 7), which suggested that PFOS molecules can not occupy the interlayers of kaolinite. In contrast, as shown in Fig. 7, a broad peak at a $d$-spacing of $1.19 \mathrm{~nm}$ for the wet paste of montmorillonite without PFOS adsorption indicated the existence of interlayer hydration with monolayer of water molecules $[44,45]$. Upon PFOS adsorption, a slight increase in $d(001)$ spacing from 1.19 to $1.24 \mathrm{~nm}$ was observed, which is consistent with a previous report on expansion from 1.34 to $1.46 \mathrm{~nm}$ [46]. The magnitude of the $d$-spacing increase $(0.05 \mathrm{~nm})$ was significant less than the molecular sectional size of PFOS (OD: $\approx 0.40 \mathrm{~nm}[9]$ ), which indicated that PFOS may partially insert into interlayers of montmorillonite during the adsorption. In conclusion, our XRD results indicated that interlayer adsorption existed on montmorillonite, whereas no interlayer adsorption occurred on kaolinite.

\subsection{Effects of HA coating}

To simulate the natural particulate assembly where clay minerals are associated with organic matter, HA was coated on kaolinite and montmorillonite [19] with the concentration of 60 and $32 \mu \mathrm{g}$ $\mathrm{Cg}^{-1}$ (Table S1), respectively. PFOS adsorption experiments were then performed on such HA-kaolinite and HA-montmorillonite to exploit the impact of the coated HA. The results in Fig. 1 

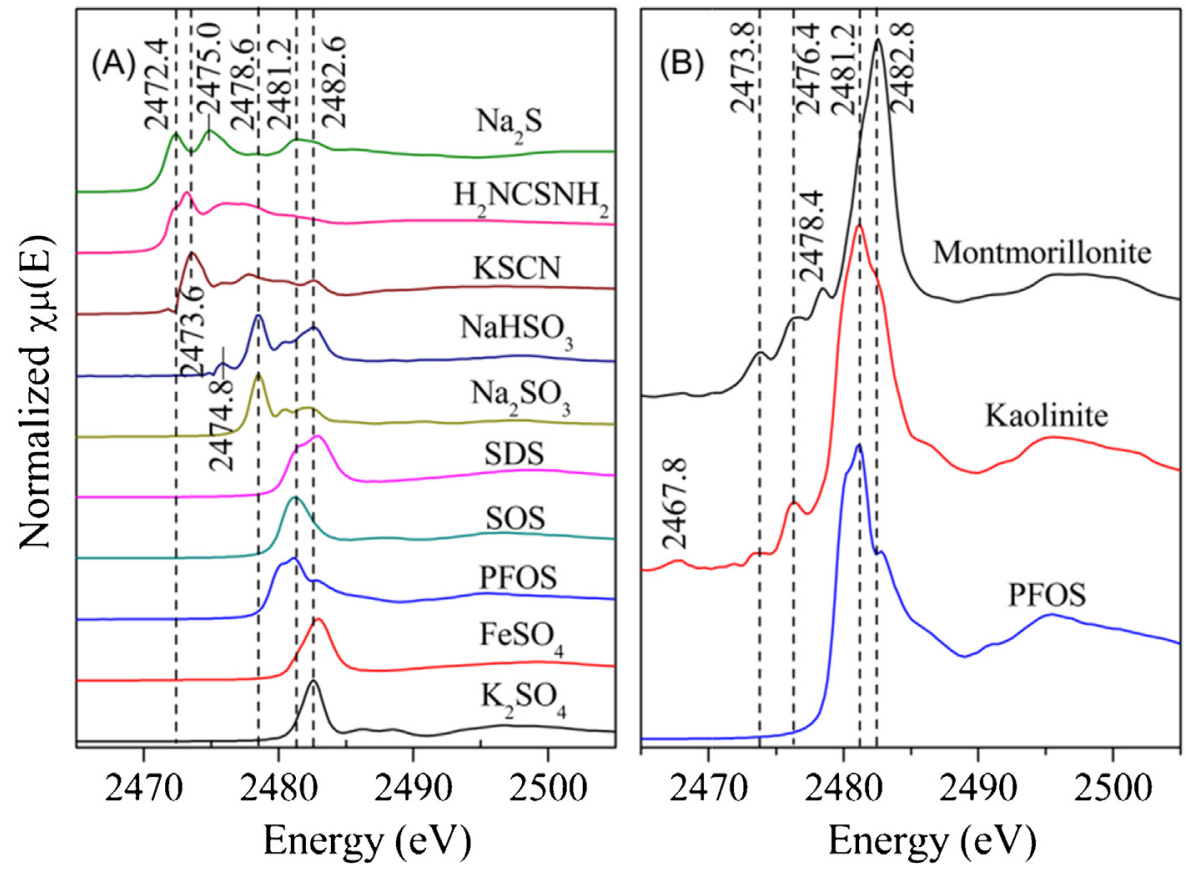

Fig. 6. Sulfur K-edge NEXAFS spectra of PFOS and PFOS adsorbed on two clay minerals.

showed that the coated HA decreased PFOS adsorption by $19.8 \%$ on kaolinite and by $25.3 \%$ on montmorillonite. This adsorption decrease could be attributed to the negatively charged HA, which may inhibit PFOS adsorption due to adsorption site occupancy and electrostatic repulsion. The HA coating may increase the electrostatic repulsion between FFOS and clay minerals because HA coating decreased the zeta potential of the particle (Fig. 2).

Our FTIR analysis also confirmed the adverse effect of HA coating on PFOS adsorption. The FITR results showed the $\mathrm{Si}-\mathrm{O}$ vibration at $1006,1031,1090 \mathrm{~cm}^{-1}$ on kaolinite and $1095 \mathrm{~cm}^{-1}$ on montmorillonite disappeared upon HA coating (Figs. 3 and 4) $[10,47]$, suggesting adsorption sites occupation by HA. In addition, the intensity of $\mathrm{C}-\mathrm{F}$ bond decreased by $4.8 \%$ and $68.0 \%$ on HA-kaolinite and HA-montmorillonite, respectively (Fig. 5). However, PFOS adsorption kinetics were not changed in the presence and absence of coated HA (Table S4), suggesting the HA coating would not affect the adsorption mechanisms. The significant

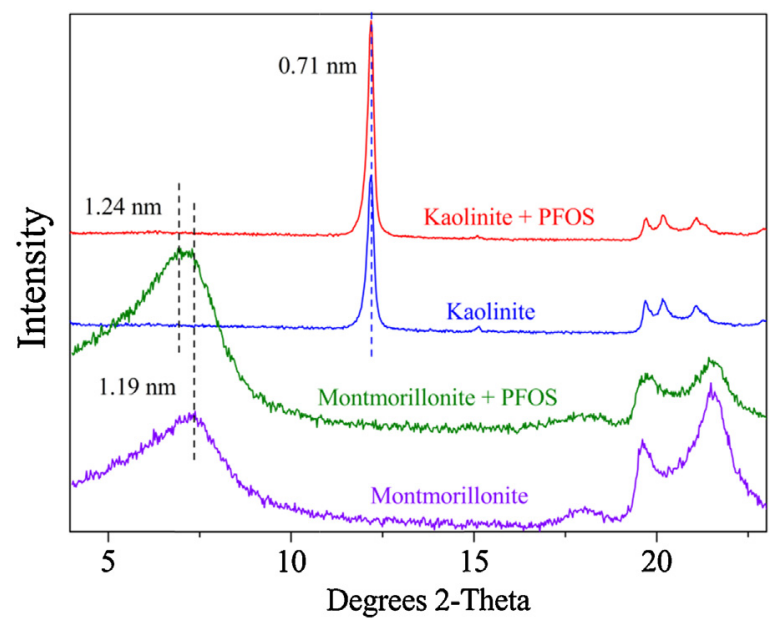

Fig. 7. X-ray diffraction patterns of kaolinite and montmorilonite wet paste adsorbed with and without PFOS at pH 7.0 in $10 \mathrm{mM} \mathrm{NaCl}$. discrepancy of PFOS adsorption decrease by HA coating may be caused by the fact that HA occupied most of the available adsorptive sites on montmorillonite but a large amount of sites still remained on kaolinite.

Contrast to our results, previous study reports that sediment organic carbon should be attributable to PFOS uptake due to hydrophobic partitioning, in which the PFOS distribution coefficient was linearly increased with the organic carbon content increasing from $0.6 \%$ to $9.7 \%$ [16]. The contrast observations may be due to the amount of HA on surfaces. The high content of HA (OC, 0.6-9.7\% [16]) in sediment could serve as organic phase to absorb PFOS, whereas minor HA $(<0.1 \%)$ on surface may compete with PFOS for adsorption. The results highlight the complex impact of $\mathrm{HA}$, the major composition of nature organic carbon, on the fate and transport of PFOS.

\section{Conclusions}

The mechanistic understanding of PFOS adsorption on clay minerals in the presence of humic acid is a fundamental basis in evaluating its fate, transport, and toxicity. The hydrophobic and electrostatic interactions play an important role in PFOS adsorption on kaolinite and montmorillonite, and therefore PFOS mainly forms outer-sphere surface complex. In addition to non-specific physical interactions, specific chemisorption also exists between sulfonate group of PFOS and hydroxyl group on surfaces of clay minerals. Interlayer intercalation can influence the PFOS adsorption, depending on the structure of the clay minerals: no interlayer adsorption exists for PFOS on kaolinite, whereas interlayer insertion occurs on montmorillonite. When the surface of minerals is coated with humic acid, the adsorption of PFOS could be inhibited due to the electrostatic repulsion and occupation of adsorption sites. These dissolved humic substances, once adsorbed on minerals under natural conditions, may hinder the adsorption of PFOS onto clay minerals. Our results highlight the importance of clay minerals and humic acid on the adsorption of PFOS and its fate and transport in the environment. 


\section{Acknowledgments}

We acknowledge the financial support of the National Basic Research Program of China (2014CB441102), Strategic Priority Research Program of the Chinese Academy of Sciences (XDB14020201), and the National Natural Science Foundation of China (41023005 and 21321004).

\section{Appendix A. Supplementary data}

Supplementary data associated with this article can be found, in the online version, at http://dx.doi.org/10.1016/j.colsurfa. 2014.09.019.

\section{References}

[1] L. Zhang, J.G. Liu, J.X. Hu, C. Liu, W.G. Guo, O. Wang, H. Wang, The inventory of sources, environmental releases and risk assessment for perfluorooctane sulfonate in China, Environ. Pollut. 165 (2012) 193-198.

[2] F. Xiao, K.J. Davidsavor, S. Park, M. Nakayama, B.R. Phillips, Batch and column study: sorption of perfluorinated surfactants from water and cosolvent systems by Amberlite XAD resins, J. Colloid Interface Sci. 368 (2012) 505-511.

[3] D. Brooke, A. Footitt, T. Nwaogu, Environmental Risk Evaluation Report: Perfluorooctanesulphonate (PFOS), UK Environment Agency, 2004

[4] K.J. Hansen, H.O. Johnson, J.S. Eldridge, J.L. Butenhoff, L.A. Dick, Quantitative characterization of trace levels of PFOS and PFOA in the Tennessee River, Environ. Sci. Technol. 36 (2002) 1681-1685.

[5] A. Beyer, D. Mackay, M. Matthies, F. Wania, E. Webster, Assessing long-range transport potential of persistent organic pollutants, Environ. Sci. Technol. 34 (2000) 699-703.

[6] R. Bossi, F.F. Riget, R. Dietz, C. Sonne, P. Fauser, M. Dam, K. Vorkamp, Preliminary screening of perfluorooctane sulfonate (PFOS) and other fluorochemicals in fish, birds and marine mammals from Greenland and the Faroe Islands, Environ. Pollut. 136 (2005) 323-329.

[7] G. He, G. Pan, M. Zhang, Assembling structures and dynamics properties of perfluorooctane sulfonate (PFOS) at water-titanium oxide interfaces, J. Colloid Interface Sci. 405 (2013) 189-194.

[8] N.R. Haria, G.S. Grest, C.D. Lorenz, Viscosity of nanoconfined water between hydroxyl basal surfaces of kaolinite: classical simulation results, J. Phys. Chem. C 117 (2013) 6096-6104.

[9] F. Xiao, X. Zhang, L. Penn, J.S. Gulliver, M.F. Simcik, Effects of monovalent cations on the competitive adsorption of perfluoroalkyl acids by kaolinite: experimental studies and modeling, Environ. Sci. Technol. 45 (2011) 10028-10035.

[10] K. Wang, B. Xing, Structural and sorption characteristics of adsorbed humic acid on clay minerals, J. Environ. Qual. 34 (2005) 342-349.

[11] Y. Tsujimoto, C. Chassagne, Y. Adachi, Comparison between the electrokinetic properties of kaolinite and montmorillonite suspensions at different volume fractions, J. Colloid Interface Sci. 407 (2013) 109-115.

[12] C.D. Hatch, J.S. Wiese, C.C. Crane, K.J. Harris, H.G. Kloss, J. Baltrusaitis, Water adsorption on clay minerals as a function of relative humidity: application of BET and freundlich adsorption models, Langmuir 28 (2012) 1790-1803.

[13] G. Sposito, N.T. Skipper, R. Sutton, S.-H. Park, A.K. Soper, J.A. Greathouse, Surface geochemistry of the clay minerals, Proc. Natl. Acad. Sci. U.S.A. 96 (1999) 3358-3364.

[14] R.L. Johnson, A.J. Anschutz, J.M. Smolen, M.F. Simcik, R.L. Penn, The adsorption of perfluorooctane sulfonate onto sand, clay, and iron oxide surfaces, J. Chem. Eng. Data 52 (2007) 1165-1170.

[15] C.Y. Tang, Q. Shiang Fu, D. Gao, C.S. Criddle, J.O. Leckie, Effect of solution chemistry on the adsorption of perfluorooctane sulfonate onto mineral surfaces, Water Res. 44 (2010) 2654-2662.

[16] C.P. Higgins, R.G. Luthy, Sorption of perfluorinated surfactants on sediments, Environ. Sci. Technol. 40 (2006) 7251-7256

[17] B. Gu, J. Schmitt, Z. Chen, L. Liang, J.F. McCarthy, Adsorption and desorption of natural organic matter on iron oxide: mechanisms and models, Environ. Sci. Technol. 28 (1994) 38-46.

[18] X. Wang, X. Shan, L. Luo, S. Zhang, B. Wen, Sorption of 2,4,6-trichlorophenol in model humic acid-clay systems, J. Agric. Food. Chem. 53 (2005) 3548-3555.

[19] K. Yang, B. Xing, Sorption of phenanthrene by humic acid-coated nanosized $\mathrm{TiO}_{2}$ and $\mathrm{ZnO}$, Environ. Sci. Technol. 43 (2009) 1845-1851.

[20] L. Weng, W.H. Van Riemsdijk, L.K. Koopal, T. Hiemstra, Adsorption of humic substances on goethite: comparison between humic acids and fulvic acids, Environ. Sci. Technol. 40 (2006) 7494-7500.

[21] C.V. Chrysikopoulos, V.I. Syngouna, Attachment of bacteriophages MS2 and (X174 onto kaolinite and montmorillonite: extended-DLVO interactions, Colloids Surf. B 92 (2012) 74-83.
[22] W. Yan, S. Hu, C. Jing, Enrofloxacin sorption on smectite clays: effects of pH cations, and humic acid, J. Colloid Interface Sci. 372 (2012) 141-147.

[23] G. Pan, C.X. Jia, D.Y.Zhao, C. You, H. Chen, G.B. Jiang, Effect of cationic and anionic surfactants on the sorption and desorption of perfluorooctane sulfonate (PFOS) on natural sediments, Environ. Pollut. 157 (2009) 325-330.

[24] C.Y. Tang, Q.S. Fu, A.P. Robertson, C.S. Criddle, J.O. Leckie, Use of reverse osmosis membranes to remove perfluorooctane sulfonate (PFOS) from semiconductor wastewater, Environ. Sci. Technol. 40 (2006) 7343-7349.

[25] Y. Yang, W. Yan, C. Jing, Dynamic adsorption of catechol at the goethite/aqueous solution interface: a molecular-scale study, Langmuir 28 (2012) 14588 14597.

[26] R. Alonso Mori, E. Paris, G. Giuli, S.G. Eeckhout, M. Kavčič, M. Zîitnik, K. Bučar, L.G.M. Pettersson, P. Glatzel, Electronic structure of sulfur studied by X-ray absorption and emission spectroscopy, Anal. Chem. 81 (2009) 65166525.

[27] B. Ravel, M. Newville, Athena, artemis, hephaestus data analysis for X-ray absorption spectroscopy using IFEFFIT, J. Synchrotron Rad. 12 (2005) 537-541.

[28] X. Gao, J. Chorover, Adsorption of perfluorooctanoic acid and perfluorooctane sulfonic acid to iron oxide surfaces as studied by flow-through ATR-FTIR spectroscopy, Environ. Chem. 9 (2012) 148-157.

[29] X. Feng, A.J. Simpson, M.J. Simpson, Chemical and mineralogical controls on humic acid sorption to clay mineral surfaces, Org. Geochem. 36 (2005) 1553-1566.

[30] C.L. Lai, J.H. Harwell, E.A. O’Rear, S. Komatsuzaki, J. Arai, T. Nakakawaji, Y. Ito Adsorption isotherms of perfluorocarbon surfactants from aqueous and nonaqueous solutions and friction measurements of perfluorosurfactant-adsorbed alumina, Colloids Surf. A: Physicochem. Eng. Asp. 104 (1995) 231-241.

[31] T.H. Yoon, S.B. Johnson, C.B. Musgrave, J.G.E. Brown, Adsorption of organic matter at mineral/water interfaces: I. ATR-FTIR spectroscopic and quantum chemical study of oxalate adsorbed at boehmite/water and corundum/water interfaces, Geochim. Cosmochim. Acta 68 (2004) 4505-4518.

[32] R. Xing, S.E. Rankin, Three-stage multilayer formation kinetics during adsorption of an anionic fluorinated surfactant onto germanium. 1. Concentration effect, J. Phys. Chem. B 110 (2005) 295-304.

[33] A.G. Young, A.J. McQuillan, Adsorption/desorption kinetics from ATR-IR spectroscopy. Aqueous oxalic acid on anatase $\mathrm{TiO}_{2}$, Langmuir 25 (2009) 3538-3548.

[34] S. Asaoka, S. Hayakawa, K. Kim, K. Takeda, M. Katayama, T. Yamamoto, Combined adsorption and oxidation mechanisms of hydrogen sulfide on granulated coal ash, J. Colloid Interface Sci. 377 (2012) 284-290.

[35] H. Sekiyama, N. Kosugi, H. Kuroda, T. Ohta, Sulfur K-edge absorption spectra of $\mathrm{Na}_{2} \mathrm{SO}_{4}, \mathrm{Na}_{2} \mathrm{SO}_{3}, \mathrm{Na}_{2} \mathrm{~S}_{2} \mathrm{O}_{3}$, and $\mathrm{Na}_{2} \mathrm{~S}_{2} \mathrm{Ox}(x=5-8)$, Bull. Chem. Soc. Jpn. 59 (1986) 575-579.

[36] O.A. Baturina, B.D. Gould, A. Korovina, Y. Garsany, R. Stroman, P.A. Northrup Products of $\mathrm{SO}_{2}$ adsorption on fuel cell electrocatalysts by combination of sulfur K-edge XANES and electrochemistry, Langmuir 27 (2011) 14930-14939.

[37] G. Sarret, J. Connan, M. Kasrai, G.M. Bancroft, A. Charrié-Duhaut, S. Lemoine, P. Adam, P. Albrecht, L. Eybert-Bérard, Chemical forms of sulfur in geological and archeological asphaltenes from Middle East, France, and Spain determined by sulfur K- and L-edge X-ray absorption near-edge structure spectroscopy, Geochim. Cosmochim. Acta 63 (1999) 3767-3779.

[38] J.R. Prietzel, A. Botzaki, N. Tyufekchieva, M. Brettholle, J.R. Thieme, W. Klysubun, Sulfur speciation in soil by S K-edge XANES spectroscopy: comparison of spectral deconvolution and linear combination fitting, Environ. Sci. Technol. 45 (2011) 2878-2886

[39] B.O. Leung, F. Jalilehvand, R.K. Szilagyi, Electronic structure of transition metalcysteine complexes from X-ray absorption spectroscopy, J. Phys. Chem. B 112 (2008) 4770-4778.

[40] A. Dey, M. Chow, K. Taniguchi, P. Lugo-Mas, S. Davin, M. Maeda, J.A. Kovacs M. Odaka, K.O. Hodgson, B. Hedman, E.I. Solomon, Sulfur K-edge XAS and DFT calculations on nitrile hydratase: geometric and electronic structure of the nonheme iron active site, J. Am. Chem. Soc. 128 (2005) 533-541.

[41] N. Okude, M. Nagoshi, H. Noro, Y. Baba, H. Yamamoto, T.A. Sasaki, P and S Kedge XANES of transition-metal phosphates and sulfates, J. Electron. Spectrosc. Relat. Phenom. 101-103 (1999) 607-610.

[42] W. Xiong, J. Peng, Y. Hu, Use of X-ray absorption near edge structure (XANES) to identify physisorption and chemisorption of phosphate onto ferrihydritemodified diatomite, J. Colloid Interface Sci. 368 (2012) 528-532.

[43] J. Majzlan, S.-C.B. Myneni, Speciation of iron and sulfate in acid waters: aqueous clusters to mineral precipitates, Environ. Sci. Technol. 39 (2005) 188-194.

[44] F.-R.C. Chang, N.T. Skipper, G. Sposito, Computer simulation of interlayer molecular structure in sodium montmorillonite hydrates, Langmuir 11 (1995) 2734-2741.

[45] N. Skipper, G. Sposito, F.-R.C. Chang, Monte Carlo simulation of interlayer molecular structure in swelling clay minerals. 2. Monolayer hydrates, Clays Clay Miner. 43 (1995) 294-303.

[46] Q. Zhou, S. Deng, Q. Yu, Q. Zhang, G. Yu, J. Huang, H. He, Sorption of perfluorooctane sulfonate on organo-montmorillonites, Chemosphere 78 (2010) 688-694.

[47] S. Kang, B. Xing, Phenanthrene sorption to sequentially extracted soil humic acids and humins, Environ. Sci. Technol. 39 (2005) 134-140. 